\title{
Teaching the Pilots of the New Millennium: Adult Cooperative Education in Aviation Education
}

\author{
Joseph F. Clark, III \\ Embry Riddle Aeronautical University
}

\begin{abstract}
Aviation is a very dynamic field that requires great dedication on the part of those who choose professional flying for their careers. Students must acquire a great amount of knowledge to include technical data, procedural information, social skills and more. There is much for the potential aviator to learn; sometimes it seems overwhelming to the initiate.

One means of learning this vast amount of information involves the technique of cooperative education. The mixing of adult educational techniques and cooperative learning may be particularly useful in aviation. Using cooperative education in acquiring the required knowledge can teach them discipline and social skills required in surviving today's active aviation environment.

The challenge then, becomes one for the college-level aviation instructor. This paper addresses techniques for teaching potential pilots the fundamentals required for the job based on adult and cooperative educational techniques.
\end{abstract}

\section{INTRODUCTION}

According to Telfer \& Moore (1997), there are three approaches to learning. These include surface learning, deep learning, and achievement.

Surface learners are dependent on rote learning and tend to acquire only minimal knowledge. These learners tend to be anxious over what they have learned and accomplish only the minimal work necessary. Deep learners, on the other hand, have grasped the concept that learning is a means to understanding, which gives meaning to what they have learned. The highest learners, the achieving learners, are those who do very well. These learners tend to be very competitive, with egos that can only be satiated by a higher standard of learning.

In aviation, student pilots must achieve a level of learning that will allow them to solve problems from a well-defined knowledge base while interacting with others. Motivation plays a very important part of the equation.

Training the students, then, becomes a question of increasing their knowledge base with meaningful activities that will allow interaction among the students. To this end, the instructor needs to develop learning exercises that will challenge the students in small groups. Such exercises can include team competition regarding knowledge of regulations, aerodynamics, meteorology, navigational exercises, and more.

Cooperative Training in the Classroom

Cooperative education in the classroom is the idea of teamwork in a practical sense. Students must realize that in order to succeed, they have to be willing to work in a team environment. From personal observation and discussion with students, this is an idea older students are apt to more readily accept than their younger peers. These older students include those returning 
to school from a tour of duty in the military, or those who have been in the business world working to save money for school.

Johnson, et al. (1991) points out the five elements of cooperative learning in the classroom. The first is the idea of positive interdependence. To establish positive interdependence, an instructor must assign tasks requiring students to work together toward a common goal. Within the task, each student becomes responsible for a portion of the assignment, and must depend on the others of the group to do their work as well. In the end, each student will learn to trust one another and realize a decrease in their individual workloads.

The second element includes the idea of face-to-face interaction. Working together will enhance the sense of trust and camaraderie among those involved in a project.

The third element is that of individual accountability. Each student within the group must be able to count on others of the group to carry his or her load.

The fourth element is the development of social skills. Working in a group will train students to work well with others, express their ideas, lead when appropriate and follow when acting as part of the team.

The last element of cooperative learning is that of group processing. The idea of group processing is that of the group maintaining its identity as a group, and the continuance of further development and use of the social skills needed for additional growth.

\section{The Nature of Aviation Training}

Airline aviation can be a very harsh and demanding field desired by many young high school graduates enrolling in collegiate aviation programs at the start of the new millennium. While many 17- and 18-year old high school graduates find the airline industry attractive, many are ignorant of the skills required to accomplish their goals. The new students are also independent from home for the first time, away from their parents and other constraints of their family situations. As college freshmen, they desire treatment as adults, but are at times unable to stay focused on simple tasks. These new students are an independent lot, still trying to figure out what they have to do in order to progress through their academics. Some are still learning some of the most basic concepts of life, one of which is the idea that "divided we fall, united we stand" (Johnson, Johnson, \& Smith, 1991).

The challenge for aviation professors is teaching young students in a manner the students find palatable. In order to do this, treating new students as young adults is the key. One problem with teaching recent high school graduates is that some are still in the mindset of pedagogical learning. Many perceive that some higher authority dictates what they must learn; a few have come to the realization that learning is something pleasant giving them a true thirst for knowledge, particularly aviation knowledge.

Many colleges and universities still hold learning to be a competitive and individualistic endeavor. In some disciplines, this is true. Cooperative education, however, is more suited to the aviation industry because pilots will be dealing with others throughout their entire careers - specifically, through Crew Resource Management (CRM). In this context, they need to develop the social skills that will allow them to interact in a positive way with flight crewmembers, air traffic controllers, operational dispatchers, and others. When they learn together, student aviators will acquire more information and skills in a shorter time while enhancing social skills and developing teamwork skills, all of which are important for successful candidates in the airline 
industry.

While the freshman or sophomore college student is in an aviation class addressing their interests in flying, they enter college and aviation training with learned educational habits they must overcome. In other words, they have to learn how to seek knowledge and become less dependent on professors to supply information. According to Knowles (1990), adult learning is "a process of active inquiry, not passive reception." Unfortunately, some of the secondary school systems in the United States tend to develop and foster attitudes towards "passive reception" (Knowles, 1990).

This passive reception conditioning of students by the secondary school system reinforces the idea or attitude of the individuals that they are merely students. From discussions with younger students who entered college straight from high school, many feel as if they had to go to college because of others' expectations. A number of students enroll in college driven by parental influences rather than personal internal desires to seek knowledge. Consequently these students are not truly ready for school; more importantly, they have not developed the techniques for learning on their own. Therefore, common perception holds these students are dependent on professors, teachers, instructors, and others for more than standard guidance in their learning.

In his work titled, "Aviation education and adult learning: an integrated learning model," Karp (1998) points out "adults are voluntary, practical learners who pursue education for its use to them." More mature college students may have come to this realization. Some of the younger set, however, has yet to make this distinction in their educational lives.

One way to foster independent learning in younger college students is by introducing them to peer pressure through cooperative learning techniques. "When adults teach and learn in one another's company, they find themselves engaging in a challenging, passionate, and creative activity." (Brookfield, 1986.) In the aviation field, students find themselves attracted by activities that are already "challenging and passionate." From discussions with active flight instructors, the problem with younger students is that what they view as challenging and passionate is the actual stick and rudder work in the airplane. As with many who have preceded them, they quickly determine that learning the fundamentals and required regulatory knowledge to survive in the National Airspace System can be boring.

Unfortunately, in the aviation field the fundamentals and required knowledge comprise a large amount of information. To some, the amount of information is daunting, almost to the point of exasperation. The essential aviation knowledge can be so intimidating that many new students start their training, only to drop out in a very short time.

Students who drop out typically have not matured enough to understand that they alone are responsible for seeking out knowledge. These students also tend to think as children rather than as adults. They tend to be singularly competitive rather than team players. Students who resist team projects and peer learning do not understand that by way of cooperative learning, they can increase their knowledge far beyond their individual capabilities while doing so in a much shorter time. By working in a team and sharing the workload, students can increase their comprehension more than they are able "solo." The result is they can reach their educational goals more thoroughly and quickly (Johnson, et al. 1991).

Attitudes Toward Learning

The major difference between the 
methods by which an immature student thinks compared to the more mature student lies in their attitudes toward learning. As noted above, the undeveloped student still thinks in terms of the subject matter that he or she must learn as dictated. This results in a natural resistance on their part to acquiring the requisite subject matter knowledge. On the other hand, fully developed learners realize the need for the knowledge and are self-directed toward attainment of their educational goals.

In teamwork, or in an atmosphere of cooperative learning on an adult level, the more advanced students will help the undeveloped students along in the learning process. In so doing, they in turn reinforce their own learning. This idea of teamwork or cooperative education on the part of the students is very important in the aviation field.

Although it is a cliché, pilots must learn the knowledge of their chosen profession as if their lives depend on it. For in fact, their lives and the lives of others truly do depend on how well they learn the cognitive information required of aviators. To this, the learner must add the eye-hand coordination essential for the safe operation of an aircraft.

As Johnson, et al. (1991) point out the use of cooperative learning techniques in the classroom, coupled with a reduction in competition, will aid students in learning a greater amount of information in more depth. Specifically, as Johnson's group writes, "More efficient and effective exchange and processing of information take place in cooperative than in competitive or individualistic situations."

While students of aviation are competitive in nature and will eventually be competing against one another later in the industry, they will have to learn to work with others. In the cockpit, students will become team players from the standpoint that they will work within a crewed environment. In that environment, competition is undesirable and tends to inhibit safety. Consequently, part of the aviation training pilots should undergo during training must include the cooperative aspects of team membership.

\section{Cooperative Aviation Education}

Using cooperative

learning techniques in the classroom has benefits and disadvantages. Some students are naturally resistant to working in a team environment, preferring to work alone. From discussions with students, the reasons offered most often include a fear of having their grade depend on the work of another. Consequently, the instructor must design the evaluation process to assuage student concerns regarding their lack of control over their final grade.

One of the first issues at the beginning of a term is assigning students to learning teams (Kohlruss \& Moren, 1998). The instructor must accomplish this task in a manner to create groups of strong and weak personalities. If left to the students, they will naturally create cliques of their friends. This will result in a polarized class of strong groups and weak, rather than diverse groups.

This grouping may be somewhat acceptable, but in the areas of developing social skills and working with relative strangers, the instructor must assign students randomly into groups of differing social, educational, and ethnic backgrounds (Kohlruss, et al. 1998). In aviation, this is important in refining a potential pilot's abilities to work well in a demanding environment with others.

The question then is one of assigning students to teams in a random manner. There are many techniques for this; the class can be counted off in the number of groups which would have all the one's on the first team, all the two's, and so on. This 
technique does not guarantee student assignment into teams of diversity. In other words, all the females in the class could end up on one team by accident, a situation depriving others the opportunity to work with women in aviation (Kohlruss, et al. 1998).

Another technique for dividing the class into teams would include such ideas as using the last number of the student's identification number; drawing team numbers from a hat; using student mailbox numbers and dividing them into groups such as the lower third, middle third, and upper third (Kohlruss, et al. 1998). Only the professor's imagination limits the procedure for dividing the class into teams.

One approach to assuring diversity and assigning individuals with strong personalities to teams including those with weaker personalities is through personal observation and questionnaires. At the beginning of the term, the professor can administer the questionnaire to determine who has strengths in leadership and experience in aviation and who does not. By waiting and observing the class for two or three periods, he or she can then determine who are the leaders and followers. The instructor can then manipulate assignments as necessary (Kohlruss, et al. 1998).

\section{$\underline{\text { Specific Aviation Exercises }}$}

The process of teaching all of the information required to work as a professional pilot is extensive. Traditional classroom technique will not allow students to acquire all the required knowledge in one conventional term. Therefore, the key to helping students grasp all the information possible is by cooperative learning.

By assigning the students projects in teams, they can share the learning and the workload and attain higher degrees of learning. The means to accomplishing this goal is through group assignments that are simpler in the beginning of the term and become more complex toward the end.

For a typical commercial/multiengine class, Appendix A illustrates a typical first exercise. Broken into groups of three to six, students work on the project as a team. Within the group, one individual will emerge as a natural leader/manager and begin delegating responsibility to others in completing the different areas of the assignment. This individual takes charge as the captain with the others of the group responding as crewmembers. This may be appropriate for the first exercise, but in later exercises, others in the group must also act in leadership roles. To this end, the instructor may have to apply some direction to the group dynamics.

The typical first exercise is a crosscountry flight planning task. As illustrated by Example Exercise 1 of Appendix A, the drill is simple and straightforward. It provides students the direction required to apply knowledge already acquired to a problem. The students have to reference aspects of commercial aviation regulations, multi-engine flying, and other problems pertinent to carrying out the flight in a safe manner.

As the course progresses through the term, the exercises become more complex, as illustrated in Example Exercise 2 of Appendix B. As teams, the students must solve problems related to the exercise, taking into consideration the possible outcomes of specific scenarios.

Throughout the term, the students deal with more complex issues of highaltitude and turbine operations. They must now apply the introductory information gained in solving the cross-country training exercise and indeed, delve into more information on their own. 
Evaluation and Assigning Grades

One problem with cooperative education is determining grades for individuals and teams within the class. Many in education feel as though testing is contrary to the learning process (Dean, 1994). While a few educators may feel as though testing is not necessary, there are many more line captains and other aviators who will demand new aviators not only be tested, but also meet predetermined minimum scores.

In his book, Designing Instruction for Adult Learners, Dean (1994) gives five reasons for the necessity of evaluation. These include enhancing the self-awareness of the student; increasing student selfesteem; development of communicational skills; determining future learning requirements; and finally, the question of certification and credentials.

In determining student grades, professors must consider the level of individual participation in group projects and assignments. A system of peer evaluation may be helpful in this regard, but the instructor or professor must realize a bias may become a part of the peer evaluation process paralleling the popularity of certain individuals within the group.

Evaluation of students is necessary for several reasons. Dean (1994) classified seven domains for evaluation. These include:

1. Learner's reactions to the learning experience.

2. Information.

3. Problem-solving skills.

4. Psychomotor skills.

5. Affective factors such as attitudes, values, and feelings.

6. Personal growth and development.

7. Changes in the organization or community.
In the business of flying airplanes, the cognitive domain is very consequential. The required knowledge is a phenomenal amount and must be available for recall -- no matter the situation. There will be times during an aviator's career that the stress of an emergency may prevent him or her from being able to recall and use the information properly.

Another important area that will interest line captains, training officers, and other management is the problem-solving skills of the newly certified pilot. This is a field that is as significant as the psychomotor, or stick-and-rudder abilities of the new pilot.

Finally, every potential employer of the next generation of pilots will be interested in the values and attitudes of the recently licensed. If a new pilot has unsafe habits or attitudes that result in dangerous practices, chances are minimal in the hiring or further re-training of the individual.

Potential employers of recently certified aviators will be interested in the aviator's total cognitive knowledge, abilities, and flying skills. In short, they will want to know if the students know their business, are capable of solving problems, are safety conscious, and have stick-and-rudder skills.

The job of the aviation professor then, is to make the learning fun, assure each student gains the required knowledge, and then by way of assigning grades, advise future employers the degree to which the students have learned their lessons.

Studwell (1992) identified nine important teaching principles in teaching adult students. At the top of the list are knowing the student, relating their experience to the learning, and accounting theory to actual practice.

Today's aviation students are very intelligent and motivated, but for different reasons. Some seek the high paying airline positions while others simply want to learn 
how to fly. As Studwell suggests, you have to know the individual student and be able to deal with each on a one-to-one basis. What motivates one may not necessarily motivate another.

The key then is providing worthwhile common learning activities for all to share in. By knowing the students as well as possible, the common denominator can be determined. Then the facilitator can develop plans consisting of meaningful group exercises in which cooperative learning for the group can take place.

Studwell goes on to say instructors must arrange an environment conducive to learning. Within this environment, they should use different formats and teaching techniques to enhance student learning.

For the student, there should be some form of feedback to the instructor regarding the course, the subject matter, and teaching. Additionally, resources for learning must be readily at hand. The easier it is for the students to physically acquire the material, the more learning will take place (Studwell, 1992).

Another important point Studwell brings up is developing and maintaining contact with the student, other than academically. In many instances, how students interact with their instructors, peers, and others can influence their success or failure in an aviation academic program. A professor who facilitates, rather than taking on the traditional role of a teacher, is necessary for the students' realization of "a state of self-actualization or to become fully functioning persons," according to Brookfield (1986).

An important element brought up by Brookfield, supporting Studwell's recommendations, is that the instructor must have a genuine concern for his or her students. Brookfield also mentions that teachers must be experts in their fields and capable of relating theory to practice.
Those facilitating student learning must also be confident in their teaching abilities while providing a positive environment in which learning can take place. Additionally, Brookfield relates that instructors and teachers must be openminded toward the ideas and concepts of the students. They should also be able to help direct students to additional learning beyond the objectives of the curriculum.

Brookfield (1986) makes the argument for professors helping their students learn rather than being "didactic instructors who know all the answers." To this end, Brookfield cites Tough (1979) in the description of the characteristics shared by successful teachers. These characteristics include 1) being a warm and caring person; 2) respecting the student's self-direction; 3) treating the learners as their equals; and 4) having an open-minded attitude.

\section{$\underline{\text { Practical Recommendations }}$}

The first and most important is to know the student. In the cockpit, this is very easy. One-on-one training allows personalities to mesh easily allowing strangers to become friends in short order. In the aviation classroom, however, it is a different story. Getting to know the students is dependent on other factors such as the size of the class. Secondly, the instructor must develop learning experiences that will interest all students in the class. Identifying and applying a common interest among the group can do this.

Another consideration identified by Studwell is making the environment conducive to learning. Many instructors do not have an input regarding the physical aspects of the class other than perhaps the thermostat in the classroom, but they do have a say in the manner in which the class is conducted. In other words, each student should feel comfortable enough to speak his or her mind. 
Another important aspect a professor or instructor must accomplish is that of communication. The students should feel comfortable enough to discuss the class freely and there has to be genuine communication between instructor and student.

Finally, as noted by Brookfield above, instructors should help their students learn. The professor who deals with students on an equal level will go further in helping students learn than one who exudes an air of superiority. Essentially, this requires the instructor not to judge each student, but to teach each student.

Many aspire to the characteristics described above. (Some facilitators are good, and some professors are not.) An instructor, a professor, a lecturer, and the teacher -- all are names applied to those charged with the duty of helping others learn. Despite the name, the job of teaching is the most important component helping people learn. The key to being successful in helping students learn is treating them as you would like to be treated. 


\section{REFERENCES}

Brookfield, Stephen. (1986). Understanding and facilitating adult learning. San Francisco, CA: Jossey-Bass.

Dean, Gary J. (1994). Designing instruction for adult learners. Malabar, FL: Krieger Publishing Company.

Johnson, David W., Johnson, Roger T., \& Smith Karl A. (1991). Cooperative learning: increasing college faculty instructional productivity. ASHE-ERIC Higher Education Report No. 4 Washington D.C.: The George Washington University, School of Education and Human Development.

Karp, Merrill R. (1998). Aviation education and adult learning: an integrated learning model. In Daniel Findahl (Ed.). Flight instructor conference, proceedings, Elevating our profession. (pp. 151-158). Daytona Beach, FL: Embry-Riddle Aeronautical University.

Knowles, Malcom S. (1990). The adult learner: a neglected species. Houston, TX: Gulf Publications Company.

Kohlruss, W. \& Moren, C. (1998, August). Cooperative Learning Techniques. Paper presented at the faculty meeting of the Aeronautical Science Department of Embry-Riddle Aeronautical University, Daytona Beach, FL.

Studwell, Regina (1992). Development of a student handbook for the college of continuing education of Embry-Riddle Aeronautical University. University Microfilms International Dissertation Information Service. 1707.

Telfor, Ross A. \& Moore, Phillip J. (1997). Aviation training: learners, instruction and organization. London: Ashgate Publishing, Ltd. 


\section{APPENDIX A. EXAMPLE EXERCISE 1}

Mod I Exercise

PA-44 Seminole

Pilot 185

Front passenger $\quad 144$

Rear passenger 198

Baggage 60

Fuel as required

For weight and balance data, use Seminole N1234X

Departure point: Naples, FL

Destination: Savannah, GA

Departure time: $\quad$ This Wednesday, February 3, 1999 at 0800 local, use actual weather observations and forecasts for flight planning.

Prepare full flight plan, with regards to a commercial operation.

Prepare full flight log, including weight and balance data to the destination including fuel stops if necessary.

Due date: Monday, February 8 


\section{APPENDIX B. EXAMPLE EXERCISE 2}

Team Leader:

Member:

Member:

Member:

Member:

\section{High Altitude Cross Country Exercise}

Houston Hobby to Reno International

Please use the copy command to replicate this page on a Word format and then answer the questions. Remember this is a team effort and the answers should reflect the consensus of the team, not just one member.

Upon completion of the answer sheet, please staple it to the nav log and turn in the complete package on Thursday or Friday as appropriate.

1. What did your team determine to be the gross weight at departure?

2. What did your team determine to be the total moment at departure?

3. What did your team determine to be the center-of-gravity at departure?

4. What route did you choose to get around the weather?

5. What was the maximum allowable fuel on departure?

6. What was your arrival time at Reno (local and Zulu)?

7. What was the total mileage along your chosen route?

8. What was the average ground speed along the first leg?

9. What was the average ground speed along the second leg?

10. What was the ETE for the first leg?

11. What was the ETE for the second leg?

12. What was total time for the trip including a $0+45$ refueling stop?

13. If you had a rapid decompression at exactly 2 hours and 20 minutes into the trip on the first leg of the trip, what action would you take? (Not airplane specific, generic actions only.) 
14. What kind of approach would you expect for landing at Reno?

15. What is the landing distance going to be at Reno and what are some of the considerations you will take into account? 